\title{
Cross-Border Rent Shifting in International Telecommunications
}

\author{
Douglas A. Galbi* \\ Senior Economist \\ Federal Communications Commission \\ Washington, DC 20554
}

February 17, 1998

\begin{abstract}
While scholars have questioned the merits of strategic trade policy, such policies have played a major role in international telecommunications. Countries have traditionally linked bilaterally their termination prices for international telephone calls. I show that this linkage can be rationalized as a mutually beneficial constraint on rent seeking. Linkage becomes more challenging to maintain with telecommunications liberalization, competition, and the growth of alternatives for terminating traffic. I consider possible policy approaches to such developments. Overall, this case study suggests that constraining cross-border rent shifting will present a major transitional challenge in international efforts to liberalize services.
\end{abstract}

Note: The published version of this paper is in Information Economics and Policy 10 (1998): 515-536. This pre-publication draft is freely available from www.galbithink.org

\footnotetext{
* The views expressed in this paper are those of the author and do not necessarily reflect the views of the Commission or its staff.
} 


\section{Introduction}

Cross-border rent seeking has long been a subject of policy analysis and concern. The notion of economic development as a zero-sum game has deeply rooted popular appeal. At an analytic level, both the traditional discussion of optimal tariffs and the newer literature on strategic trade policy recognize that under imperfect competition policies can be implemented that extract or shift rents internationally. ${ }^{1}$ Such concerns have never been confined merely to measures applied at national borders. Competition policy scholars have noted that export cartels have commonly received exemptions under the exporting country's competition policy. ${ }^{2}$ Privatization and liberalization of state-owned industries, the globalization of investment, and the growth of trans-border service markets have increasingly placed national competition and regulatory policies into debates about the cross-border shifting of value.

International telecommunications provides an insightful case study of the issues and policy challenges that arise from cross-border rent seeking. National governments, typically acting through state-owned telecommunications service providers, have been able to exercise monopoly power in exporting communications services (such as terminating international calls) to foreigners wanting to buy the associated international service (making international calls). ${ }^{3}$ As the competition policy exemptions for export cartels suggest, extracting value (rents) from foreign consumers has significant appeal to national

\footnotetext{
${ }^{1}$ The theory of the optimal tariff, and its limitations, are discussed in any good international economics textbook. For a broad collection of papers on strategic trade policy, see Krugman (1987).

${ }^{2}$ See, for example, OECD (1996) pp. 31-35.

${ }^{3}$ New technologies, such at the Internet, terrestrial wireless, and satellites systems, are making maintaining such monopolies increasingly difficult and costly.
} 
governments. Moreover, in the case of international voice traffic, the amount of value that can be extracted from monopoly pricing for terminating foreign-billed international calls is typically large relative to home-billed revenue for international service. ${ }^{4}$

However, rent seeking in international telephony, as in other areas, confronts a prisoner's dilemma: each country individually has an incentive to pursue such policies, but each doing so creates offsetting rent flows that make all worse off. For a simple illustration, consider two identical countries that originate and terminate the same number of international calls. In equilibrium incentives for rent seeking via increases in termination charges merely produce symmetrically higher marginal costs for international calls and no net transfers of value. An unfortunate result is higher retail prices for international calls and lower social welfare for both countries. While traffic asymmetries have implications for rent-seeking policies, telephony is nearly unique in the extent to which every country has both significant imports and exports of closely related goods (purchase of foreign termination services, sale of domestic termination services).

Domestic liberalization and competition adds another twist to this dilemma. High prices for terminating foreign-billed traffic are easy to implement when telecommunications is a national monopoly. Countries that liberalize entry and promote competition in telecommunications are likely to improve the price, quality, and range of services to domestic consumers. But such countries also face the prospect of international call termination prices being driven down to competitive levels domestically while international call termination prices in foreign countries remain high. One result could be

\footnotetext{
${ }^{4}$ See Table 1 and the subsequent discussion.
} 
a significant transfer of value abroad, at least until other countries implement procompetitive reforms.

While these issues are attracting significant interest among policy-makers, the literature addressing them is only beginning to develop. Kwerel $(1984 ; 1987)$ considers the effect of increasing competition among U.S. international carriers while Stanley (1991) describes the problem of ballooning net U.S. international payments in telecommunications. O'Brien (1989) provides an interesting theoretical analysis of the effect of requiring uniform international termination prices among U.S. carriers. Hakim and Lu (1993), Carter and Wright (1994), Cave and Donnelly (1996), and Yun, Choi, and Ahn (1996) present models of the determination of international termination prices and consider policy implications. Scanlan (1997) provides an insightful analysis of proportional return and call-back. These papers, however, tend to focus more on carrier profitability than social welfare. Frieden (1997) reviews some of the issues from a multilateral perspective, and Einhorn (1997) provides a good review of the related theoretical and empirical literature. ${ }^{5}$

This paper attempts to clarify the economic logic, empirical significance, and policy implications of cross-border rent seeking in international telephony. Section 2 sets out the potential appeal of cross-border rent seeking, while Section 3 shows that the traditional institutional structure of international telephony, known as the accounting rate system, can be understood as a means for constraining rent seeking. Section 4 indicates that, without policies to address the problem, cross-border rent shifting under asymmetric national liberalization significantly decreases a country's incentive to liberalize unilaterally. 
Section 5 discusses how cross-border rent shifting can be constrained by regulatory rules that eliminate direct competition among domestic carriers for terminating foreign-billed minutes. Section 6 briefly considers two alternative policies. Section 7 suggests some insights that this case study might offer for understanding international economic relations in a world of progressive but uneven economic liberalization and expanding transnational service markets.

\section{A Simple General Equilibrium Model}

A simple general equilibrium model is useful for analyzing the welfare effects of crossborder rent seeking in international telephony. The model has two countries with corresponding attributes denoted by superscripts $\mathrm{H}$ (home country) or F (foreign country). In each country a representative citizen consumes three goods: international telephone (and fax) calls $T$ that the citizen places, food, and leisure. Assume that a representative citizen's utility function can be expressed as a function of $T$ and of a composite good $G$, where $G$ incorporates a fixed trade-off between food and leisure. Citizens in each country work in respective national telecommunications monopolies which have as their only input their citizens' labor and which redistribute any profits equally to their citizens.

The utility function for a representative citizen in the home country is:

(1) $U^{H}\left(T^{H}, G_{0}^{H}+\Pi^{H}+R^{H}-p_{R}^{H} T^{H}\right)$, where

(2a) $\Pi^{H}=\left(p_{R}^{H}-c_{o}^{H}-p_{T}^{F}\right) T^{H}$

(2b) $R^{H}=\left(p_{T}^{H}-c_{T}^{H}\right) T^{F}$

\footnotetext{
${ }^{5}$ This is a large body of literature on domestic interconnection issues. See Mueller (1996), Ralph (1996), Armstrong, Doyle, and Vickers (1995), and Katz, Rosston, and Anspacher (1995), among others.
} 
$G_{0}^{H}$ is the citizen's initial endowment of food and leisure, $\Pi^{H}$ is profit per (home) citizen from home-billed international traffic, $R^{H}$ is revenue per citizen from terminating foreignbilled traffic, $p_{R}^{H}$ is the retail price per minute for home-billed international traffic, $T^{H}$ is home-billed international traffic per citizen, and $p_{T}^{H}$ and $c_{T}^{H}$ are the price and net cost per minute, respectively, for terminating foreign-billed traffic in the home country. ${ }^{6}$ Cost represents lost leisure from laboring to provide the given service. ${ }^{7}$

In the international voice industry, $p_{R}^{H}$ is commonly referred to as a collection rate and $p_{T}^{H}$ is called a settlement rate.

Foreign-billed traffic is $T^{F}$ per home citizen. Note that the utility function does not recognize that home citizens derive utility from receiving foreign-billed calls. Such utility could be incorporated in the model through an ad hoc adjustment of $c_{T}^{H}$.

Suppose that the national regulator or the national telecommunications operator chooses retail and termination prices to maximize its representative citizen's welfare. Let $c_{o}^{H}$ be the cost per minute of originating an international call in the home country. Then the home regulator or operator will set

(3) $p_{R}^{H}=c_{o}^{H}+p_{T}^{F}$

The foreign regulator or operator will set foreign retail prices similarly. Recognizing this, the home regulator or operator will maximize $(2 \mathrm{~b})$ by setting

(4) $p_{T}^{H}=\frac{c_{T}^{H} \varepsilon^{F}-c_{o}^{F}}{1+\varepsilon^{F}}$

\footnotetext{
${ }^{6}$ Note that there are a large number of representative consumers. Hence from an individual consumer's perspective, his or her choice of $\mathrm{T}^{\mathrm{H}}$ does not affect $\Pi^{\mathrm{H}}$.
} 
where $\mathcal{E}^{F}$ is the foreign price elasticity of demand at price $p_{R}^{F}=c_{o}^{F}+p_{T}^{H}$. This elasticity, which is negative, must be greater than 1 in absolute value in an equilibrium. ${ }^{8}$ The price for terminating home-billed minutes in the foreign country will have a form analogous to (4).

This model shows export monopolies setting rent-maximizing termination prices. While some national authorities apparently advocate such a regime, ${ }^{9}$ it does not currently exist in international telephony. Simple calculations suggest why. Consider the United Kingdom, for which the number of home-billed and foreign-billed international minutes are nearly equal (Oftel, 1997). Reasonable parameters for $c_{T}^{H}, \varepsilon^{F}$, and $c_{o}^{F}$ for the U.K. might be 3.5 pence (not including receiver benefits), -1.2 , and 5 pence. ${ }^{10}$ These parameters and (4) imply an U.K. rent-maximizing international termination price of 46 pence per minute. The average U.K. termination price for international minutes between April 1995 and March 1996 was 20 pence per minute (Oftel, 1997). Thus while the actual price is well above cost, the rent-maximizing price would be yet $130 \%$ higher. At the rent-maximizing

\footnotetext{
${ }^{7}$ In this (non-monetary) general equilibrium model, prices and revenue should be expressed in units of food; nonetheless, food can be equated with money to allow conventional understandings of prices and revenue. ${ }^{8}$ If at a given price the elasticity of demand facing the operator is less than 1 in absolute value, the operator will raise its price. The operator will continue to raise its price while its elasticity of demand is less than 1 in absolute value. This is a general feature of models where firms have price-setting power.

${ }^{9}$ Advocating that international termination prices be set unilaterally according to a self-determined costing methodology or according to arbitrary accounting conventions is essentially equivalent to giving individual countries the ability to set rent-maximizing termination prices.

${ }^{10}$ Garín Muňoz and Pérez Amaral (1996) find a -0.77 price elasticity of international minutes for Spain, 19851989. Hackl and Westlund (1995) find prices elasticities of international minutes around 1 during 1986-1991 for Germany, U.K., Denmark, Norway, and Finland. They also find that the price elasticities for these countries increased over time. Industry Commission (1997) used a price elasticity of -1.2 for Australia. I have chosen this value as a reasonable parameter for the calculations here. The cost estimates are generally consistent with Industry Commission (1997) and FCC (1997a). FCC (1996) Table 6.6 indicates that, for U.S.local exchange companies together with AT\&T, customer operations expenses amounted to $23 \%$ of total operating expenses in 1994 . Since long distance and international carriers face much more competition than local exchange carriers, their expenses on retail marketing and customer support are likely to be larger. I have thus assumed that originating traffic costs about a third more than terminating traffic.
} 
price, rents from foreign-billed traffic would amount to $62 \%$ of home-billed international revenue. $^{11}$

There is reason to consider the above calculation conservative and to estimate even higher values for a rent-maximizing termination price. First, many operators maintain high international calling prices for their customers, implying that an effective $c_{o}^{F}$ might be significantly higher than 5 pence. Second, there is evidence that international call demand in some countries is less elastic than assumed above. ${ }^{12}$ Third, the extent to which cost reductions are passed through into retail prices depends on demand characteristics and the nature and extent of competition; with imperfect competition pass-through of cost reductions to retail prices may be significantly less than one. These factors suggest that a rent maximizing termination price might be significantly higher than 46 pence per minute.

High international termination prices have significant welfare costs. In a symmetric world, each country's attempt to shift rents toward itself are exactly offset by other countries' similar efforts. The result is simply to raise the marginal cost, and hence the retail price, of international calls. ${ }^{13}$ Even with somewhat asymmetric traffic flows, most countries could be worse off under a regime of rent-maximizing termination prices. ${ }^{14}$

\footnotetext{
${ }^{11}$ This calculation assumes that foreign retail prices increase by 74 percent, as would be the case if the average foreign retail price was the same as the U.K. average retail price ( 35 pence) and the increase in the termination price ( 26 pence) was passed through into the average retail price. The calculation used recognizes that foreignbilled traffic would fall to $51 \%$ of home-billed traffic because of this increase in price.

${ }^{12}$ Some countries do not provide itemized telephone bills or effectively disseminate prices. Such informational limitations make demand less elastic.

${ }^{13}$ Note that, absent proportional return and "return call" effects, the cost of sending an additional outgoing call, which is the relevant factor for setting profit-maximizing retail prices, does not depend on the balance of traffic. Confusion between average settlement cost and marginal cost is pervasive in the industry.

${ }^{14}$ Calibrating the model in Section 5 for the U.S. and the rest of the world shows that, even with a U.S. outbound to inbound international traffic ratio of 2.2 to 1 , both the U.S. and the rest of the world are better off under the mutual termination price constraint discussed in Section 3 than under rent-maximizing termination prices.
} 
Moreover, while only one party to a telephone call typically pays, a call is a jointly consumed good. During the reference period used above, U.K. consumers paid on average 35 pence per minute for the international calls billed to them. If they valued receiving foreign-billed calls at half that rate, terminating foreign-billed calls would represent a net contribution to domestic social welfare. If companies or regulators do not fully recognize the consumer gains from receiving calls, the welfare cost of a rentmaximizing regime for international call termination would be even higher.

\section{Linkage as a Constraint on Rent Extraction}

In international telephony an institutional structure developed that effectively disciplines an individual country's incentive to raise termination prices for foreign-billed traffic. This institutional structure, known as the international accounting rate system, links foreign and domestic international call termination prices across country pairs. The linkage in practice has generally been of the form $p_{T}^{H}=p_{T}^{F}$, and the common value will be labeled $p_{s}$. In the international voice industry the value referred to as the accounting rate is $p_{T}^{F}+p_{T}^{H}=2 p_{s}$.

The general equilibrium model described in Section 2 can be used to analyze the effect of this new constraint. As before, welfare maximizing national regulators or operators set retail prices according to (3) and its foreign country analogue. A representative citizen in the home country maximizes (1) by choosing $T^{H}$ such that
(5) $\frac{d U^{H} / d T^{H}}{d U^{H} / d G^{H}}=p_{R}^{H}$, where
(6) $G^{H}=G_{0}^{H}+R^{H}-p_{R}^{H} T^{H}$ 
Now consider the value of $p_{s}, p_{s}^{H}$, that maximizes home country welfare. Such a $p_{s}^{H}$ satisfies (for an interior solution)

(7) $-\frac{d G^{H} / d p_{s}}{d T^{H} / d p_{s}}=\frac{d U^{H} / d T^{H}}{d U^{H} / d G^{H}}=p_{R}^{H}$

Note that

$$
d G^{H} / d p_{s}=T^{F}-T^{H}+\left(p_{s}-c_{T}^{H}\right) d T^{F} / d p_{s}-\left(p_{s}+c_{o}^{H}\right) d T^{H} / d p_{s}
$$

In contrast to the maximization of $R^{H}$ in Section 2, (8) incorporates an interdependency between the prices for terminating home-billed and foreign-billed traffic. Combining and simplifying (7) and (8) yields

(9) $\frac{T^{H}}{T^{F}}=1-\frac{p_{s}^{H}-c_{T}^{H}}{p_{s}^{H}+c_{o}^{F}}\left(-\varepsilon^{F}\right)$

While recognizing that $T^{H}$ and $T^{F}$ are functions of $p_{s}^{H},(9)$ can be written as

(10) $p_{s}^{H}=\frac{c_{T}^{H} \mathcal{E}^{F}-c_{o}^{F}+c_{o}^{F} \frac{T^{H}}{T^{F}}}{1+\varepsilon^{F}-\frac{T^{H}}{T^{F}}}$

The foreign country's preferred mutual settlement rate, $p_{s}^{F}$, would be given by an equation analogous to (10). Bargaining between the home and foreign carriers (or governments) over the range that $p_{s}^{H}$ and $p_{s}^{F}$ define would produce the actual settlement rate, $p_{s}$.

To see the effects of constraining termination prices, one would like to compare the above situation to that analyzed in Section 2. Suppose that home and foreign costs and elasticities of demand are identical, so that the rent-maximizing termination prices (see 
(4)) are the same for the home and foreign countries. ${ }^{15}$ Comparing (4) to (10) shows that, irrespective of the magnitude of the traffic ratio, both countries prefer a lower mutual (i.e. linked ex ante) termination price than the rent-maximizing termination price. Assuming appropriate second order conditions are satisfied, both countries are better off at some mutual termination price lower than the rent-maximizing price. In particular, with the traffic ratio equal to 1 , the mutual termination price equals cost, $p_{s}=c_{T}^{H}=c_{T}^{F}$. Relative to the equilibrium with the rent-maximizing termination price, both countries have higher welfare, and the outcome is in fact the global welfare maximum.

Linking termination prices across countries mitigates rent-seeking incentives. Consider again the U.K. example presented above. The U.K.'s rent-maximizing termination price, for the parameters given, is 46 pence per minute. Since the U.K.'s traffic ratio with the rest of the world is close to $1,(10)$ indicates that with linked termination prices the U.K. prefers a termination price equal to its cost of terminating international traffic, $c_{T}^{H}$, taken in the example to be 3.5 pence per minute. The large difference between the U.K. rent-maximizing termination price and its preferred mutual termination price demonstrates the effect of linkage in mitigating rent-seeking incentives.

The U.K., like most other countries, actually has mutual termination prices on a bilateral basis. The U.K.'s average termination price for international traffic, 20 pence per minute (Oftel(1997), while considerably lower than the calculated rent-maximizing price, is also significantly higher than the calculated mutual price. Several factors may help account for this difference. Cost and demand characteristics in the rest of the world

\footnotetext{
${ }^{15}$ Note that there could still be a traffic imbalance. A simple parametrization of such a situation in this model is to assume that the total number of representative consumers differs across the home and foreign countries.
} 
may not be identical to those in the United Kingdom, hence the rest of the world may have a different (higher) preferred mutual rate. Moreover, aggregating the rest of the world into a single correspondent may not adequately capture some implications of the countryspecific bargaining process. Modeling the actual mutual rate is likely to be difficult. The important lesson from the above analysis is that a mutual rate, by blunting incentives for rent shifting, can significantly reduce international call termination prices.

There has been some discussion of settlement systems involving asymmetric settlement rates. Such a system can be described as $p_{T}^{F}=k p_{T}^{H}$, where $k$ is a given positive constant. The accounting rate is thus $p_{T}^{F}+p_{T}^{H}=(1+\mathrm{k}) p_{T}^{H}$. If, for example, $\mathrm{k}=2$, this rule would be a "two-thirds/one-third split of the accounting rate". Other values of $k$ produce different divisions of the accounting rate. Incorporating these variations into the above analysis produces an equation like equation (10) but with $k \frac{T^{H}}{T^{F}}$ replacing $\frac{T^{H}}{T^{F}}$. The analogous equation for the foreign country would have $\frac{1}{k} \frac{T^{F}}{T^{H}}$ replacing $\frac{T^{F}}{T^{H}}$.

The above model provides some insight into bargaining over the mutual termination price. Equation (10) and its foreign-country analogue show how cost differences can generate differences in preferred mutual prices. Equation (10) and its analogue also show that a country sending more home-billed minutes $\left(T^{H}\right)$ than it receives in foreign-billed minutes $\left(T^{F}\right)$ will prefer a mutual termination price below its cost of terminating traffic. The opposite is true for the corresponding foreign country. As the traffic imbalance increases, the country sending more traffic prefers a higher settlement rate while the country receiving more traffic prefers a lower one. 
Equation (10) can be used to provide an estimate of the likely difference in positions of two countries coming together to bargain over settlement rates. New technologies and new routing possibilities, such as call-back, reorigination/refile, and internet telephony, can cause large and volatile traffic imbalances. These industry trends suggest that large traffic imbalances, rather than differences in costs or demand elasticities, are likely to be increasingly the key factor accounting for the differences in desired settlement rates. ${ }^{16}$ Asymmetric divisions of the accounting rate, perhaps associated with cost differences, would be closely tied to traffic imbalances in determining the effect on desired settlement rates. While one might assume that the contentiousness of bargaining would be directly related to magnitude of the difference between desired outcomes, the ultimate outcome of accounting rate bargaining is much harder to analyze.

\section{Implications of Asymmetric Liberalization and Competition}

Domestic policy has important implications for linking foreign and domestic international call termination prices. A regulator, or the operator itself, could easily establish such a link when the national telecommunications industry is a monopoly. However, governments have increasingly recognized the value of telecommunications liberalization and competition. Yet domestic competition could easily break the link between domestic and foreign prices for terminating corresponding international calls. International call termination prices could be driven down to competitive levels domestically while international call termination prices in foreign countries could remain high, or no longer

\footnotetext{
${ }^{16}$ The cost and uncertainty associated with such bargaining are important reasons for moving away from the convention of "traffic direction" and per minute prices as the basis for interconnection compensation. For a related discussion, see Galbi (1998b).
} 
disciplined by a link to call termination prices in the corresponding country, they could rise to the rent-maximizing level. ${ }^{17}$

The rents that could potentially shift away from a liberalizing country are large relative to industry magnitudes. Table 1 shows rough estimates of the effect of unilateral liberalization for each of the listed countries. I assume that effective liberalization brings international call termination prices down to 6 U.S. cents per minute in the given country while termination prices in the rest of the world remain constant. Across large economies the revenue shifts are on the order of a billion dollars per year and average around $25 \%$ of home-billed international call revenue. ${ }^{18}$

\footnotetext{
${ }^{17}$ A somewhat similar concern about asymmetric liberalization arose regarding the 1984 AT\&T divestiture on the U.S. telecommunications equipment industry. The divestiture separated Western Electric, AT\&T's equipment subsidiary, from the regional Bell Operating Companies (RBOC's). The divestiture thus improved the opportunities of foreign telecommunications equipment manufactures to sell equipment to the RBOC's. Because foreign telecommunications companies did not undertake similar reform, it was argued that the divestiture created an international competitive disadvantage for Western Electric. As it turns out, AT\&T subsequently recognized competitive advantages of spinning off its equipment subsidiary, which became Lucent Technologies.

${ }^{18}$ These rent shifts are much larger, in terms of the percentage of industry revenue, than those estimated in studies of strategic trade policy. Krishna, Hogan, and Swagel (1994) estimated that the gains from optimal U.S. trade intervention in its automobile industry ranged from $\$ 1.7$ billion in 1980 to $\$ 13$ billion in 1985. The latter figure amounts to $15 \%$ of the value of U.S. retail automobile sales in 1985 . Welfare gains from optimal tariffs or subsidies for nine industries in six European countries were, with one exception, less than $2.5 \%$ of retail sales and were typically less than $1 \%$ of retail sales (Venable(1994)). Rent shifts from asymmetric telecommunications are also more certain than those associated with strategic trade policy. In the Brander and Spencer (1984) analysis of the optimal response to foreign cartelization, optimal policy depends on the second derivative of the demand curve. In contrast, calculations of rent shifts from asymmetric telecommunications liberalization depend only on figures for quantities and prices.
} 
Table 1

Revenue Loss from Unilateral Liberalization

\begin{tabular}{|l|c|c|c|}
\hline Country & $\begin{array}{c}\text { Revenue Loss } \\
\text { (mil. US\$) }\end{array}$ & $\begin{array}{c}\text { As \% of home- } \\
\text { billed int'l revenue }\end{array}$ & As \% of GDP \\
\hline Australia & 200 & $35 \%$ & $.06 \%$ \\
\hline Germany & 1,200 & $30 \%$ & $.05 \%$ \\
\hline Japan & 800 & $25 \%$ & $.02 \%$ \\
\hline United Kingdom & 1,100 & $45 \%$ & $.10 \%$ \\
\hline United States & 2,100 & $15 \%$ & $.03 \%$ \\
\hline $\begin{array}{l}\text { Notes: The figures are estimates for 1995. The figures for Australia, the United Kingdom, and } \\
\text { the United States are calculated from data in Industry Commission (1997), Oftel (1997), and FCC } \\
\text { (1997), respectively. Traffic and revenue figures for Germany and Japan are from ITU and } \\
\text { Telegeography (1996). The average incoming termination price for Germany is assumed to be the } \\
\text { same as that for the U.K. The average incoming termination price for Japan is assumed to } 50 \% \\
\text { higher than that of Australia, since Japan has a much larger share of international traffic with } \\
\text { relatively high-termination-price countries such as China and the Republic of Korea. }\end{array}$ \\
\hline
\end{tabular}

The rough calculations in Table 1 ignore several potentially important effects. The calculations ignore the effect on traffic magnitudes of any potential changes in retail prices. If the liberalizing country's termination price falls, foreign retail prices for calling the liberalizing country may fall in response to this reduction in the marginal cost of placing a call. In the liberalizing county, international calling prices might rise as a result of the reduction in the profitability of terminating foreign-billed international calls. Such a change in retail prices would lessen the revenue shift associated with liberalization, both because of direct price effects on calling volumes and because of call direction choices made at the customer level (who calls whom; whether one party asks the other party to “call back").

The calculations also ignore any effects of the reduction in termination prices on carriers offering call-back services. In the U.S., non-competitive termination prices coupled with proportional return have produced low wholesale rates for international calls from the U.S. These low wholesale rates have in turn been a strong impetus for the 
growth of U.S. based call-back operators. If U.S. termination prices unilaterally fell to 6 U.S. cents per minutes, wholesale rates for international calls from the U.S. would rise. Hence costs for U.S. based call-back operators offering services abroad would also rise. A resulting reduction in call-back traffic from the U.S. would reduce U.S. outgoing international traffic and increase U.S. inbound international traffic. Nonetheless, while call-back currently has great significance in some markets, its overall significance is small. The call-back industry has revenue of about US\$1 billion. In contrast, U.S. carriers had international revenue of about US\$15 billion in 1997 and all carriers had international revenue totaling about US\$65 billion. A reduction in call-back traffic would not have a significant effect on the overall traffic balance of the U.S. or any other large country. ${ }^{19}$

Alternative routing methods, know under various terms such as transiting, refiling, hubbing, third-country routing, and re-origination, can mitigate differences in termination prices across a given country's international interconnection arrangements. Small, new carriers tend to use such routing for most of their traffic while established carriers tend to use these arrangements for marginal or incremental traffic. Note, however, that alternative routing methods cannot mitigate an overall high rates for termination, and a country could still adopt a rent-maximizing uniform termination price.

The effect of a home country liberalization on foreign countries' termination prices is also uncertain. Table 1 assumes that foreign termination prices remain constant. But if

\footnotetext{
${ }^{19}$ Asymmetric liberalization and competitive termination is not likely to result in traditional traffic being redirected toward the liberalizing country via call-back. Countries that do not liberalize do not have a wholesale markets for outgoing international traffic or domestic call origination. Thus call-back operators cannot reflect traffic from or redirect traffic through a country that has not liberalized. The monopoly operator could offer such arrangements, but it would not do so in order to undercut its own settlement rents. This means that call-back is not a mechanism for bypassing a non-liberalized country's high international termination rates.
} 
home and foreign termination prices are delinked by liberalization, foreign termination prices might then rise to a rent-maximizing level (see (4)). On the other hand, carriers or the government in the liberalizing country might take retaliatory action to offset the development of a termination price gradient. Such action, or the implicit threat of such action, could result in a reduction in foreign termination prices. As industry observers have noted, the proportion of international revenue accounted for by operators that have provided international service for less than 15 years is still less than $10 \%$, and this percentage has not changed dramatically since $1991 .^{20}$ Existing international routing arrangements and revenue flows are held together by well-established business relationships along with a fear of retaliation in the face of a deliberate, provocative change. ${ }^{21}$ The effect of asymmetric liberalization on such relationships is difficult to prejudge.

The Internet over time will play an increasingly important role in international interconnection. Internet telephony can exploit least-cost routing much more cheaply and flexibly than the traditional circuit-switched international telephone network. Hence internet telephony will greatly facilitate arbitrage of termination price gradients across countries. Moreover, since internet telephony is an application that can be placed on a communications infrastructure of much more general use than a telephony network, internet telephony will facilitate the use of alternative infrastructure, i.e. data networks, for bypassing the traditional telephony network. Nonetheless, most industry analysts expect

\footnotetext{
${ }^{20}$ Mandela and Greenman (1997).

${ }^{21}$ Liberalization of international licensing and whole-circuit ownership of international facilities have provided important new by-pass opportunities in Europe and the U.S. Nonetheless, strategic concerns and a mutual interest in sustaining high prices can help sustain high interconnection prices. Proportional return also helps to sustain the
} 
that internet telephony will account for only a small share of voice traffic within the next several years. $^{22}$

While the figures in Table 1 are only rough estimates, the important insight to take from Table 1 is that the traditional settlement rate system provided the framework for determining the division of significant potential rents. Over time technological and industry change is likely to undermine the importance of this means of constraining and dividing rents. Industry participants are still grappling with the nature of this change. Telstra, for example, has argued that when it wants to install additional internet capacity to an operator in the U.S., or presumably to an operator in any other country as well, the operator in the other country should pay for half the cost of the international capacity that Telstra desires. This argument represents a projection onto the Internet of the old halfcircuit concepts of the traditional telephony settlement system and bilateral correspondence.

The technological and economic reality of the Internet clashes sharply with important aspects of the traditional telephony settlement system. From a technological perspective, the Internet is a dynamically routed packet cloud, not a series of bilateral connections, and the destination of traffic over any particular link is neither determinate nor stable. More fundamentally, the value of services provided over the Internet will be

traditional settlement system in the face of by-pass opportunities. Thus, for example, the licensing of ISR on the U.S.-U.K. route did not bring about an immediate collapse of settlement rates. See Galbi (1998a).

${ }^{22}$ Schema, a London-based telecoms consultancy, predicts a 10-15\% migration of Europe's international traffic to the internet over the new few years. See Jones (1997). Action Information Services, a U.S. telecommunications consulting firm, predicts that $4.5 \%$ of international revenues will come from internet telephony in 2001 . See Vinson (1997). Probe Research forecasts that $5 \%$ of all voice calls will be over the Internet by the year 2000, and $20 \%$ by the year 2010. See Warwick (1997). Industry analysts at a recent Voice Over the Net Conference (San Jose, March 1998) emphasized that internet telephony will depend on new applications and services and predicted that internet telephony would produce only a modest diversion of traffic from traditional networks. See http://www.pulver.com. 
orders of magnitude greater than the cost of international transport for Internet packets. Entrepreneurs are currently experimenting with a wide variety of business models for recovering the cost of creating useful content and the cost of the servers necessary to make that content available on the Internet. The nature and scope of cross-border rent shifting in a world of electronic commerce and information-based economies is far from clear, but the relevant factors are clearly much different than those associated with rent shifting under the traditional settlement system for international telephony. Thus the figures in Table 1 represent a rough estimate of a potential transitional effect on the way to a much different set of policy issues.

\section{Proportional Return: Linkage with a Competitive Market}

Under the traditional settlement system, countries that seek to foster competition domestically but want to avoid shifting rents to foreign carriers have contemplated or enacted rules to prevent direct competition among domestic carriers for terminating foreign-billed minutes. Such rules typically enforce uniform prices for terminating foreign-billed international minutes and allocate these termination services among domestic carriers in proportion to their share of home-billed international minutes. The effect is to foreclose the development of a separate market for terminating foreign-billed international calls by linking the provision of this service to competition for home-billed international minutes. This section will consider some implications of such proportional return rules.

The effect of proportional return can be analyzed with a model similar to that in Section 2, with the addition of a more explicit model of the supply of international service. 
Let $n^{H}$ be the number of home firms supplying international service. More abstractly, $n^{H}$ represents an index of the competitiveness of the home-billed international market. ${ }^{23}$ Each firm chooses a quantity $T_{i}^{H}$ of retail international minutes so as to maximize profits (Cournot competition). ${ }^{24}$ With a mutual termination price $p_{s}$ and proportional return, a firm's profit is

$$
\begin{aligned}
\text { (11) } \pi_{i}^{H} & =\left(p_{R}^{H}-c_{o}^{H}\right) T_{i}^{H}-\left(p_{s} T_{i}^{H}-\left(p_{s}-c_{T}^{H}\right) \frac{T_{i}^{H}}{T^{H}} T^{F}\right)=\pi_{i, R}^{H}-X_{i}^{H}, \text { where } \\
\pi_{i, R}^{H} & =\left(p_{R}^{H}-c_{o}^{H}\right) T_{i}^{H} \text { and } X_{i}^{H}=p_{s} T_{i}^{H}-\left(p_{s}-c_{T}^{H}\right) \frac{T_{i}^{H}}{T^{H}} T^{F}
\end{aligned}
$$

Call $\pi_{i, R}^{H}$ "originating profit" and $X_{i}^{H}$ "effective termination cost". A firm maximizes profit by setting its marginal originating profit equal to its marginal effective termination cost.

$$
\frac{d \pi_{i}^{H}}{d T_{i}^{H}}=\frac{d \pi_{i, R}^{H}}{d T_{i}^{H}}-\frac{d X_{i}^{H}}{d T_{i}^{H}}=\frac{d \pi_{i, R}^{H}}{d T_{i}^{H}}-\left(p_{s}-\left(p_{s}-c_{T}^{H}\right)\left(1-\frac{T_{i}^{H}}{T^{H}}\right) \frac{T^{F}}{T^{H}}\right)=0
$$

Equation (12) shows an important effect of proportional return. Without proportional return, the marginal effective termination cost would be the termination price $p_{s}$. Proportional return implies that sending an additional home-billed minute entitles the sender to the profit earned on its additional allocation of incoming foreign-billed traffic. A higher traffic ratio, $\frac{T^{F}}{T^{H}}$, or a higher price/cost spread for terminating foreign-billed traffic, $p_{s}-c_{T}^{H}$, increases the importance of the return traffic. Note as well that a carrier

\footnotetext{
${ }^{23}$ Other factors in addition to the number of competitors, such as the informational structure of the market, the affect of service provision on future growth opportunities, and competitors' market shares, also influence competition.
} 
with a smaller share of home-billed minutes, $\frac{T_{i}^{H}}{T^{H}}$, has a lower marginal effective

termination cost. Since proportional return favors carriers with a small share of homebilled minutes, new entrants have an incentive to support proportional return. This makes such rules more stable than usual fixed market-share allocation schemes in traditional cartels.

In general equilibrium, proportional return produces a price distortion on an input for providing international service. For a tractable welfare analysis of this distortion, assume that a representative citizen's utility function takes the form (13) $U^{H}\left(T^{H}, G^{H}\right)=\max \left(\theta-p_{R}^{H}, 0\right)+G_{0}^{H}+n^{H} \pi^{H}$ where $\theta$ is a random variable with an exponential distribution $F(\theta)=1-e^{-\lambda^{H} \theta}$. The $n^{H}$ firms supplying international service have been assumed identical. Aggregate demand for home-billed international minutes thus takes the form

(14) $T^{H}=M^{H} e^{-\lambda^{H} p_{R}^{H}}$

where $M^{H}$ can be interpreted as the (large) number of representative citizens.

Given (14), (12) implies that the Nash equilibrium satisfies

(15) $p_{R}^{H}=c_{o}^{H}+p_{s}+\Delta$, where

(16) $\Delta=\frac{1}{\lambda^{H} n^{H}}-\left(p_{s}-c_{T}^{H}\right) \frac{n^{H}-1}{n^{H}} \frac{T^{F}}{T^{H}}$

With retail price $p_{R}^{H}$, home welfare is

(17) $W^{H}=\frac{M^{H} e^{-\lambda^{H}\left(c_{o}^{H}+p_{s}\right)}}{\lambda^{H}} e^{-\lambda^{H} \Delta}\left(1+\lambda^{H} \Delta\right)+G_{0}^{H}+\left(p_{s}-c_{T}^{H}\right) T^{F}$

\footnotetext{
${ }^{24}$ In contrast to Sections 2 and 3, traffic quantities now represent gross rather than per-representative-citizen
} 
Home welfare is maximized, as expected, when $\Delta=0$, i.e. the retail price $p_{R}^{H}$ equals the social marginal cost of an additional home-billed international minute, $p_{s}+c_{o}^{H}$. Home welfare decreases as the deviation of the retail price from this level increases.

An apparent paradox exists with respect to carrier profitability. Under proportional return, a carrier's profit is

(18) $\pi_{i}^{H}=\frac{1}{n^{H}}\left(\frac{T^{H}}{\lambda^{H} n^{H}}+\left(p_{s}-c_{T}^{H}\right) \frac{T^{F}}{n^{H}}\right)$

Thus, irrespective of the traffic ratio, all carriers have higher profits with a higher mutual termination price. $^{25}$ Yet carriers in the United States, for example, have strongly supported FCC efforts to lower mutual termination prices. The more general model in Section 3 can explain the FCC's efforts: U.S. citizen's welfare would be higher if termination prices fell to the level given in (10). In light of (18), what explains U.S. carriers' interest in reducing termination prices, i.e. lowering $p_{s}$ ?

More realistic models of consumers' acquisition of price information and of oligopolistic interaction can explain this paradox. Consider a carrier with $T_{i}^{H} / T_{i}^{F}>1$, where $T_{i}^{F}$ represents the amount of foreign-billed international traffic the carrier receives. A reduction in $p_{s}$ increases the carrier's profit, given fixed retail prices. A similar effect can occur given customer costs of price information acquisition, or more generally, customer behavioral inertia. Moreover, under oligopolistic competition carriers' profits

\footnotetext{
figures.

${ }^{25}$ In a competitive market for a good with constant marginal cost of production and fixed coefficient use of an input, a change in the (common) price for that input cannot affect companies' profit margins on their value added net of that input. Termination services are an example of such an input in the model above. In this model, profit rises with the input price because proportional return does not allow all the rents on incoming traffic to be
} 
rise with a coordinated increase in price/cost margins across all competitors. A publicly known, date-certain reduction in $p_{s}$ provides a coordinated increase in price/cost margins across the industry. Thus carriers' preferences with respect to mutual termination prices reveal information about the nature of competition in international telephony.

The above model shows two types of price distortions. One distortion, which pushes up retail prices, arises from imperfect competition among home carriers. The term $1 / \lambda^{H} n^{H}$ in (16) represents this distortion. As $n^{H}$ rises, the size of this distortion decreases. Proportional return produces a second distortion. The proportional return distortion, represented by the rightmost term in (16), arises because proportional return shifts rents among home carriers when a particular carrier increases home-billed minutes. As $n^{H}$ rises, the size of this distortion increases. As (16) indicates, the distortion from proportional return acts in the opposite direction of the distortion from imperfect competition.

The evidence with respect to the United States, which tries to impose proportional return, indicates that retail prices are significantly above social marginal cost. A realistic parametrization for the U.S. (see FCC, 1997a,b) has $p_{R}^{H}=88$ cents, $c_{o}^{H}=10$ cents, $p_{s}=47$ cents, and $\left(p_{s}-c_{T}^{H}\right) \frac{n^{H}-1}{n^{H}} \frac{T^{F}}{T^{H}}=10$ cents, with $n^{H}$ taken to be 4 . The elasticity of demand, given (14), is $-\lambda^{H} p_{R}^{H}$. Taking U.S. price elasticity of international minutes to be -1.2 at a price of $\$ 1(100 \text { cents })^{26}$ implies $\lambda^{H}=.012$ and $1 / \lambda^{H} n^{H}=21$ cents. These values, all based on independent data, come together to satisfy (15). ${ }^{27}$ The calibration of (16) for

competed away. The rightmost term inside the parentheses in (18) represents the residual termination service rents.

${ }^{26}$ This is the same elasticity figure assumed for the British case. See ft. 10.

27 There is limited information available on international elasticities, and the elasticity of demand in the U.S. may be significantly less than 1.2 in absolute value. Refile and least-cost routing are also significant factors not 
the U.S. indicates that the price distortion from market power (21 cents) is greater than the offsetting price distortion from proportional return (10 cents). The difference between the average U.S. retail price and U.S. social marginal cost is the difference between these two distortions, or 11 cents.

Overall, the above model suggests several dangers associated with proportional return. Since it favors carriers with small market share, new entrants are likely to seek to perpetuate such a regime ${ }^{28}$ However, from a social perspective such a regime can cause welfare losses by pushing prices below social marginal costs. There is evidence that such a distortion has already occurred in the U.S. wholesale market for international minutes. ${ }^{29}$ Moreover, call-back operators selling U.S. dialtone have been growing rapidly. Call-back is sometimes wrongly attributed to arbitrage across U.S. and foreign international retail prices. In fact, call-back operates on the margin between U.S. wholesale rates and foreign retail rates. As indicated above, there is reason to believe that proportional return in the U.S. has significantly expanded this margin (see Scanlon (1997)).

Nonetheless, the analysis above indicates that competition in the U.S. international retail market is sufficiently imperfect to keep the average U.S. retail price above social marginal cost despite proportional return. A similar situation is likely to hold in other countries that use proportional return. This means that reforms bringing the average international retail price in line with social marginal cost would result in a reduction in the

captured in this model. Nonetheless, at the level of abstraction of this paper and in light of information available in published literature, the given parameters are realistic. They are also consistent with each other and the structure of the model.

${ }^{28}$ To see why proportional return favors carriers with a small market share, see equation (12) and the subsequent paragraph.

29 Some market participants have mentioned informally that some wholesale rates are below the termination price in the corresponding international destination. 
average retail price. As competition in the international retail market intensifies, proportional return could cause the average retail price to be driven below social marginal cost. A reform bringing price in line with social marginal cost at such a time would entail an increase in the average retail price, potentially a much less politically palatable step.

\section{Alternative Policies for Constraining Cross-Border Rent Shifting}

While policies similar to proportional return have played the most significant role thus far in addressing the risks of asymmetric telecommunications liberalization, other approaches are emerging. This section will consider two such approaches.

\section{Shifting Locus of Rent Extraction}

One simple and tempting approach is to shift rent extraction from the services that are currently the focus of competition to services that remain monopolized. This means enacting discriminatory local access charges. Chile, for example, has moved forward rapidly in promoting competition in telecommunications. At the same time Chile has allowed the local access rate for terminating foreign-billed international minutes to be set about 32 cents per minute, while the local access rate for terminating domestic long distance calls is about 6 cents per minute. ${ }^{30}$ Because competition in local access develops more slowly than competition in long distance and international services, Chile has been able to promote competition without shifting abroad rents from international traffic.

Pushing international rents down into the local bottleneck, while appealing in the short term, is likely to have significant long-term costs. In the Chilean example, reforms did not significantly shift the existing international division of rents on international traffic. 
However, shifting rents to local access is likely to exacerbate international tensions over the division of rents in the future. Shifting international rents to local access, particularly in states with a federal structure, will give the national regulator much less leverage to reduce those rents in the future. Yet it is not clear that doing so will strengthen the national regulator's bargaining power vis-à-vis other countries. Other national authorities might simply demand alternative offsetting concessions.

Pushing international traffic rents down to local access also provides a large incentive to disregard regulatory rules. A discriminatory local access regime requires carriers to truthfully characterize traffic as domestic or international. But since these distinctions are not supported by a corresponding distinction in the service provided - a minute is a minute - domestic carriers have a large incentive to misreport traffic, passing international minutes off as domestic minutes for local access purposes. Addressing concern about such action could require significant regulatory intervention and would be imperfect in any case. Overall, the large incentive to cheat and the difficulty of preventing cheating undermines the credibility of a discriminatory access regime. The resulting incentive to become a less-than-fully rule-abiding operator may also undermine other actions that the regulator takes.

Perhaps more importantly, shifting rents from international traffic to local access is likely to make the development of local competition much more politically contentious. Incumbent local carriers traditionally argue that any change that affects their revenue, i.e. competition, threatens to increase local call prices or erode universal service. Both these threats have significant political salience in a wide variety of countries. Shifting

\footnotetext{
${ }^{30}$ These rates were as of March, 1995. See AT\&T Petition (1996, p.4). MCI also made similar observations. The
} 
international rents to local access creates a much larger revenue stream that incumbent local access providers will seek to protect. The long and tortuous effort in the U.S. to reform local access charges provides a clear example of just how difficult this process can be, even when the initial level of contested rents is much lower on a per minute basis than the rents associated with terminating international traffic.

\section{Reasonable Regulatory Constraints on Termination Prices}

Another policy takes a direct approach to constraining cross-border rent shifting. In conjunction with full liberalization and competition, including non-discriminatory local access and direct competition for terminating foreign-billed international traffic, a national regulator can establish standards for the maximum rates that domestic carriers are allowed to pay to foreign carriers for terminating international traffic. ${ }^{31}$ Establishing a methodology for computing reasonable standards for terminating international traffic represents a significant but not insurmountable challenge. In the course of selecting an appropriate methodology for U.S. policy purposes, the FCC explored in detail three possibilities. ${ }^{32}$ Other countries could draw on this work, or other ongoing work in various fora, to formulate reasonable standards. While such standards may create international friction, and the FCC benchmarks have, Sections 2-4 of this paper clearly show the welfare importance of constraining rent shifting in international telephony.

However, there are dangers associated with being too ambitious in establishing price standards for international termination services. Such administratively determined price standards are a poor substitute for market-driven prices. A market for termination

applicant did not dispute the facts of the discriminatory access regime.

${ }^{31}$ The FCC has taken this type of approach. See the Benchmark Order (FCC,1997a).

${ }^{32}$ For FCC staff work on these possibilities, see FCC(1997a) Appendices C,D, and E; FCC(1997c); FCC(1997d). 
services, if such developed, would be much more effective in uncovering and evaluating relevant cost information. Market-driven prices would change rapidly and continually in response to changes in technologies and business opportunities. The stark failures of communism and market socialism show clearly that no administrative mechanism can effectively simulate market prices or maintain "true cost-based prices". Price standards for termination services should not be seen as a mechanism for simulating a non-existent market. Concrete policy concerns and regulatory trade-offs are more important than hypothetical market outcomes in thinking about the appropriate level for termination price standards.

Another danger is that price standards for international termination services might become an instrument for rent shifting rather than a safeguard against such effects. Price standards that are highly politicized and that are set with no transparent, public methodology are likely to be interpreted as instruments for rent shifting rather than as safeguards. Similarly, price standards that appear extreme in light of reasonable economic analysis and relevant empirical evidence are likely only to create mutually disadvantageous impasses. In order to be credible as a safeguard against rent shifting, price ceilings for international termination services should be expected not to bind for international points that have a significant degree of telecommunications competition and a non-discriminatory local access regime. Such standards also gain credibility if multiple countries agree upon the same set of standards.

The ITU and the WTO provide natural fora for the development of benchmarks or standards for international termination services. The WTO telecommunications agreement, which took effect 5 February 1998, was concluded with an understanding that 
accounting rate issue would be reviewed no later than the start of the next round of negotiations on 1 January 2000. Prior to such action WTO members informally agreed not to bring before the WTO complaints with respect to accounting rates. The ITU has vigorously addressed the issue of reforming international interconnection arrangements, but the outcome of these efforts is not yet clear. ${ }^{33}$ One might hope for the ITU to compile "best practice" international interconnection rates similar to those that the European Commission is using to monitor and evaluate interconnection rates within Europe. The ITU could also offer expertise for helping to elaborate further the regulatory principles for interconnection set down in the WTO Reference Paper. ${ }^{34}$

\section{Conclusions}

Cross-border rent seeking is a significant problem in international telephony. Early in the history of international telephony an institutional structure developed in which international call termination prices were linked between countries. This institutional structure, known as the accounting rate system, effectively constrains each country's incentive to exploit its monopoly in terminating international calls to parties within its national borders. Relative to a regime in which national termination prices are set at rentmaximizing levels, the accounting rate system raises global welfare, and probably the welfare of most countries as well. ${ }^{35}$

\footnotetext{
33 Reforming the international accounting rate system was a focus of the 1998 ITU World Policy Forum. See http://ties.itu.int/intset/index.htm for documents relating to the ITU's efforts.

${ }^{34}$ One might question whether significance progress is likely to be made in this area. See Drake and Noam (1997).

${ }^{35}$ In principle, using (4) a country could compute its rent-maximizing termination price and the rent-maximizing termination price of its foreign correspondents. It could then compare its welfare under such prices to its welfare under accounting rates. Note, however, that liberalization has important dynamic advantages that are not the focus of this paper. See Beltz (1998) for a discussion of first-mover advantages with respect to liberalization.
} 
Linking termination prices between countries becomes problematic with asymmetric liberalization and competition in telecommunications. Without regulatory intervention, competition among domestic carriers for terminating foreign-billed calls tends to de-link domestic termination prices from foreign termination prices and drive domestic termination prices to cost. A significant flow of rents abroad can emerge if there is no alternative discipline on foreign termination prices. The most welfare-enhancing form of discipline on foreign termination prices would clearly be effective competition in foreign markets. Some countries, however, may prevent, either as an explicit policy choice or implicitly through an absence of necessary supporting actions, the development of effective domestic competition.

There are several possible regulatory responses to asymmetric liberalization. One regulatory response is to foreclose the market for domestic termination services by administratively fixing the price for such services and using proportional return to allocate terminating foreign-billed minutes among domestic carriers. A second approach is to enact discriminatory local access charges. A third approach is to impose ceilings on the international termination prices that nationally authorized carriers are allowed to pay.

There can be little doubt, however, that the potential for private enterprise to create value is orders of magnitude greater than the potential for government policy to shift rents across national borders. In particular, effective implementation of the landmark WTO commitments in telecommunications will offer domestic welfare benefits far greater than the magnitude of rents that might be shifted between countries. Nonetheless, it is worth noting that these commitments occurred within the framework of a sector-specific negotiation. Industry-specific approaches to addressing transitional concerns about rent 
shifting may be a necessary condition for achieving multilateral international agreements to liberalize services. ${ }^{36}$

\footnotetext{
${ }^{36}$ Cross-border rent shifting is likely to be more important for services than for goods. Unlike physical goods, many services, such as communication services to reach a person in country X, shipping services to country X, land use rights in country $\mathrm{X}$, or licensing of particular intellectual property in country $\mathrm{X}$, have no close international substitutes. No other country, in the absence of supporting policies in country X, can provide the desired good. Thus such services are prone to cross-border rent shifting. Moreover, many service markets have been imperfectly competitive, if competition has existed at all. This means that large rents may be associated with the provision of these services.
} 


\section{References}

Armstrong, Mark, Chris Doyle and John Vickers, 1996, "The Access Pricing Problem: A Synthesis," Journal of Industrial Economics 44:2, pp. 131-50.

AT\&T Petition to Deny Frontier Communications Services, Inc.'s application for authority to resell private lines for the provision of switched services between the United States and Chile (1996), FCC File No. ITC-96-372.

Beltz, Cynthia, 1998, The Global Communication Revolution: The WTO and the Internet, forthcoming, AEI Press.

Brander, James A. and Barbara J. Spencer, 1984, "Trade Warfare: Tariffs and Cartels," Journal of International Economics 16, pp. 227-42.

Brock, Gerald W., 1984, Bypass of the Local Exchange: A Quantitative Assessment, OPP Working Paper Series No. 12 (FCC, Washington, D.C.).

Carter, Michael and Julian Wright, 1992, "Optimal telecommunications tariffs and the CCITT," Telecommunication Journal 59(3): 125-31.

Carter, Michael and Julian Wright, 1994, "Symbiotic Production: The Case of Telecommunication Pricing," Review of Industrial Organization 9: 365-78.

Cave, Martin and Mark P. Donnelly, 1996, "The pricing of international telecommunications services by monopoly operators," Information Economics and Policy 8: 107-23.

Drake, William J. and Eli M. Noam, 1997, “The WTO deal on basic telecommunications. Big bang or little whimper?” Telecommunications Policy 9/10: 799-818.

Einhorn, Michael A., 1997, "International Accounting and Settlements: A Review of the Literature," manuscript.

Federal Communications Commisssion of the United States (FCC), 1986, Implementation and Scope of the International Settlements Policy for Parallel Routes, 51 Fed. Reg. 4736 (1986), recon. 2 FCC 1118 (1987), further recon. 3 FCC Rcd 1614 (1988).

FCC, 1991, Regulation of International Accounting Rates, 6 FCC Rcd 3552 (1991), recon. 7 FCC Rcd 8049 (1992), Fourth Report and Order 11 FCC Rcd 20063 (1996) [Flexibility Order]. 
FCC, 1996, Statistics of Communications Common Carriers, 1995/1996 Edition (FCC: Washington, DC).

FCC, 1997a, International Settlement Rates, IB Docket No. 96-261, Report and Order, FCC 97280 [Benchmarks Order].

FCC, 1997b, Section 43.61 International Telecommunications Data (FCC, Washington, DC).

FCC, 1997c, The Use of Computer Models for Estimating Forward-Looking Economic Costs, A Staff Analysis, available on-line at http://www.fcc.gov/Bureaus/Common_Carrier/Reports/proxmod.txt.

FCC, 1997d, Model-Based Price Standards for Terminating International Traffic, Room Document No. 10, OECD/ICCP/TISP Ad Hoc Meeting on International Telecommunication Charging Practices and Procedures, 17 September 1997, OECD, Paris.

Frieden, Rob, 1997, "Falling Through the Cracks: International Accounting Rate Reform at the ITU and WTO," paper presented at the Twenty-Fifth Annual Telecommunications Policy Research Conference, Alexandria, VA.

Galbi, Douglas A., 1998a, "The Implications of By-pass for Traditional International Interconnection", forthcoming in the Proceedings of the Twenty-Fifth Annual Telecommunications Policy Research Conference, Alexandria, VA (Sept., 1997).

Galbi, Douglas A., 1998b, "Distinctive Arrangements for International Interconnection?" forthcoming in Telecommunications Policy.

Garín Muňoz, Teresa, and Teodosio Pérez Amaral, 1996, "Demand for international telephone traffic in Spain: An econometric study using provincial panel data," Information Economics and Policy 8, pp. 289-315.

Hackl, Peter, and Anders H. Westlund, 1995, "On price elasticities of international telecommunications demand," Information Economics and Policy 7, pp. 27-36.

Hakim, Sam Ramsey and Ding Lu, 1993, "Monopolistic settlement agreements in international telecommunications," Information Economics and Policy 5: 145-57.

Industry Commission of Australia, 1997, International Telecommunications Reform in Australia, available on-line at http://www.indcom.gov.au/research/papers/phones/index.html.

International Telecommunication Union (ITU) and Telegeography Inc., 1996, Direction of Traffic (ITU, Geneva). 
Jones, Phil, 1997, "Internet Telephony will Steal International Traffic," Totaltele.com, on the web at http://www.totaltele.com/cgi-bin/news.cgi/4259/worldmore.html.

Katz, Michael, Gregory Rosston and Jeffrey Anspacher, 1995, "Interconnecting interoperable systems: The regulator's perspective," Information Infrastructure and Policy 4: 327-42.

Krishna, Kala, Kathleen Hogan, and Phillip Swagel, 1994, "The Nonoptimality of Optimal Trade Policies: The U.S. Automobile Industry Revisited, 1979-1985," in Paul Krugman and Alasdair Smith, eds., Empirical Studies of Strategic Trade Policy (Univ. of Chicago Press, Chicago).

Krugman, Paul, ed., 1987, Strategic Trade Policy and the New International Economics (MIT Press,Cambridge).

Kwerel, Evan, 1984, "Promoting Competition Piecemeal in International Telecommunications," Office of Plans and Policy Working Paper Series, No. 13.

Kwerel, Evan, 1987, "Reconciling Competition and Monopoly in the Supply of International Communications Services: A U.S. Perspective," paper presented at the Center for Telecommunications and Information Studies' Conference on Asymmetic Deregulation, Paris.

Mandela, Audrey and Andy Greenman, 1997, “The Top 100 - The Usual Suspects," Communications Week International, Issue 195(24 Nov).

Mueller, Milton, 1996, "On the Frontier of Deregulation: New Zealand Telecommunications and the Problem of Interconnecting Competing Networks," forthcoming in David Gabel and David Weiman, eds., Opening Networks to Competition: the Regulation and Pricing of Access (NY: Kluwer).

O'Brien, Daniel Patrick, 1989, The uniform settlements policy in international telecommunications: A noncooperative bargaining model of intermediate product third degree price discimination, Ph.D. Dissertation, Northwestern University.

OECD, 1996, Antitrust and Market Access (OECD, Paris).

Office of Telecommunications of the United Kingdom (Oftel), 1997, Market Information Update, February 1997.

Ralph, Erik K., 1996, Regulating an Input Monopolist with a Focus on Interconnection in Telecommunications, Ph.D. Dissertation, Duke University. 
Scanlan, Mark, 1997, "Using Call-back to Demonstrate the Discriminatory Nature of the Proportional Return Rule," paper presented at the Twenty-Fifth Annual Telecommunications Policy Research Conference, Alexandria, VA.

Stanley, Kenneth B., 1991, "Balance of Payments, Deficits, and Subsidies in International Communications Services: A New Challenge to Regulation," Administrative Law Review 43(3): 411-38.

Venables, Anthony J., 1994, "Trade Policy under Imperfect Competition: A Numerical Assessment,", " in Paul Krugman and Alasdair Smith, eds., Empirical Studies of Strategic Trade Policy (Univ. of Chicago Press, Chicago).

Vinson, Jeff, 1997, "IP Telephony Could Cost Telcos \$8 Billion By 2002," Totaltele.com, on the web at http://www.totaltele.com/cgi-bin/news.cgi/7115/worldmore.html.

Warwick, Martyn, 1997, "Interactive bandwagon," Totaltele.com, on the web at http://www.totaltele.com/cgi-bin/news.cgi/6407/ci.html.

Yun, Kyoung-Lim, Hyun-Woo Choi, and Byong-Hun Ahn, 1997, "The accounting revenue division in international telecommunications: conflicts and inefficiencies," Information Economics and Policy 9, pp. 71-92. 